\title{
Causes of Contractor Cost Overrun in Construction Projects: The Case of Ethiopian Construction Sector
}

\author{
Zinabu Tebeje Zewdu ${ }^{1, ~}$, Getachew Teka Aregaw ${ }^{2}$ \\ ${ }^{1}$ Faculty of Business and Economics, Unity University and OVID Construction plc, Addis Ababa, Ethiopia \\ ${ }^{2}$ Faculty of Business and Economics, Unity University and Financial Training and Consultancy Plc, Addis Ababa, Ethiopia
}

Email address:

Zinabut@yahoo.com (Zinabu T. Z.)

To cite this article:

Zinabu Tebeje Zewdu, Getachew Teka. Causes of Contractor Cost Overrun in Construction Projects: The Case of Ethiopian Construction Sector. International Journal of Business and Economics Research. Vol. 4, No. 4, 2015, pp. 180-191. doi: 10.11648/j.ijber.20150404.11

\begin{abstract}
Completion of a construction project with budget is frequently seen as a major criterion of project success by clients, contractors, consultants and related stakeholders. It is here that project management becomes essential tool for the delivery of effective projects than the traditional functional management. However, the construction industry is faced with challenges to meet budget. This study is conducted to identify the top five cost over-run factors and survey is conducted on 140 respondents. The samples were drawn using convenient sampling approach. Primary data is collected using the self-administered questionnaires. While secondary data is collected through reviewing of related materials and the analysis is conducted using SPSS version 20. As per the contractor' response, the top five factors that causes cost overrun of construction projects were from medium to high. On the other hand, the top five factors as per the response of consultants and clients ranged between high to very high. The contractors outlined the top five factors that causes cost overrun in construction projects are poor planning, fluctuation of price of materials, poor productivity, inflationary pressure and project financing in descending order.
\end{abstract}

Keywords: Cost Overrun, Project Management, Project Control and Project Success

\section{Introduction}

Ethiopia is the fastest-growing, non-oil driven economy among African countries. The country has showed a remarkable growth over the past ten years. The average annual growth GDP is $10.9 \%$ (UNDP, 2014). This figure is double of the Sub Sahara Africa and triple of the world average growths indicating that Ethiopia is one of the fastest economic growths in the world (ibid). As a result the contribution of the industry against the GDP is only $3 \%$ and this is lower than the sub-Saharan African average which is $6 \%$. The construction industry trend in the past 10 years shows a yearly growth rate of 12.43 and this shows a share of $5.3 \%$ of the country's GDP (ECIDP, 2014).

Though the construction sector is given high prominence, several defects are being noted in the sectors that need immediate action. One significant problem is the fact that current infrastructure and construction projects show significant cost variation (ECIDP, 2014). This is occurring in spite of the fact that the Ethiopian Government played significant role in assisting contractors by providing training, supplying machinery, and by developing supportive guidance
(ECIDP, 2014).

The cost overrun on projects results in poor investment returns from the use of the project, delay in the utilization of the public facilities and extended inconvenience for the public. All of these problems exert a huge financial pressure on government, and they can hold back or impair planned economic development (Li-Yin, 2006). Hence, identification of the root causes of the challenges and pointing the possible way out in consultation with stakeholders are critical factor. In doing so, it intends to identify underlying causes for cost variation of construction projects. Moreover, it would serve as a basis for further research in the area. Such an understanding would further address the most pressing problems of human lives.

\subsection{Ethiopian Construction Sector}

The fast growth of the construction industry resulted in increasing number of contractors joining the industry. During the period 2000 up to 2008, the number of contractors increased by $1.912^{1}$. Consequently, there are 7259 numbers of

1www.mwud.gov.et accessed on March 2, 2014. 
$\mathrm{BC} / \mathrm{RC} / \mathrm{GC}$ registered contractors for 2014/15 budget year, according to the Ministry of Urban Development, Housing and Construction of Industry Development and Regulatory Bureau. Where the numbers of larger contractors up to level three are: $263 \mathrm{BC} 1 / \mathrm{RC} 1 / \mathrm{GC} 1 ; 73 \mathrm{BC} 2 / \mathrm{RC} 2 / \mathrm{GC} 2 ; 163$ BC3/RC3/GC3 (Table 1).

Table 1. Number of Contractors and Their Trend ${ }^{2}$.

\begin{tabular}{|c|c|c|c|}
\hline \multirow[b]{2}{*}{ Category } & \multicolumn{3}{|c|}{ Year of Registration } \\
\hline & $\begin{array}{l}1994 \text { E. C. } \\
(2001 / 02 \text { G. C. })\end{array}$ & $\begin{array}{l}2000 \text { E. C. } \\
(2008 \text { G. C. })\end{array}$ & $\begin{array}{l}2006 \text { E. C. } \\
(2014 / 15 \text { G. C. })\end{array}$ \\
\hline $\begin{array}{l}\text { (BC-1, GC-1, } \\
\text { RC-1) }\end{array}$ & 35 & 56 & 263 \\
\hline $\begin{array}{l}(\mathrm{BC}-2, \mathrm{GC}-2, \\
\mathrm{RC}-2)\end{array}$ & 3 & 3 & 73 \\
\hline $\begin{array}{l}(\mathrm{BC}-3, \mathrm{GC}-3, \\
\mathrm{RC}-3)\end{array}$ & 30 & 62 & 163 \\
\hline $\begin{array}{l}\text { Total from } \\
\text { Grade } 1 \text { to } 3\end{array}$ & 68 & 121 & 499 \\
\hline $\begin{array}{l}\text { Total from } \\
\text { Grade } 1 \text { to } 10\end{array}$ & 941 & 1799 & 7259 \\
\hline
\end{tabular}

Where: $\mathrm{BC}=$ Building Contractor; $\mathrm{GC}=$ General Contractor and $\mathrm{RC}=\mathrm{Road}$ Contractor

Considering the high role of the construction sector in the industry and the demand to participate more contractors in the sector, the former Ministry of Urban Development and Construction revised its guideline and developed the "Amended Directives for the registration of Construction Professionals and Contractors No. 23/2013". This directive is applied starting from July $8^{\text {th }}, 2013$. This directive allows the contractors to register in the same grade but with revised project cost up to 18 times of the old legislation (Table 1). Where, the legislation specifies that contractors of category 4 to 2 are not permitted to build above twelve floors including basement and similarly categories of 6 and 5 are not permitted to build above eight floors (Table 2).

Table 2. Project Construction Cost Review and Contractors Categories "GC", " $B C$ " and " $R C$ ".

\begin{tabular}{|c|c|c|c|c|c|}
\hline \multirow{2}{*}{ Category } & \multirow{2}{*}{ Legislation } & \multirow{2}{*}{ Grade } & \multicolumn{3}{|c|}{ Construction cost ( million Birr) } \\
\hline & & & BC & $\mathbf{R C}$ & GC \\
\hline \multirow{2}{*}{$\begin{array}{l}\text { (GC,BC,R } \\
\text { C) }\end{array}$} & Old & 1 & $\begin{array}{l}\text { Above } \\
20\end{array}$ & $\begin{array}{l}\text { Above } \\
20\end{array}$ & Above 20 \\
\hline & New & 1 & $\begin{array}{l}\text { Above } \\
210\end{array}$ & $\begin{array}{l}\text { Above } \\
300\end{array}$ & Above 350 \\
\hline \multirow{2}{*}{$\begin{array}{l}\text { (GC,BC,R } \\
\text { C) }\end{array}$} & Old & 2 & $\begin{array}{l}\text { Up to } \\
20\end{array}$ & Up to 20 & Up to 20 \\
\hline & New & 2 & $\begin{array}{l}\text { Up to } \\
210\end{array}$ & $\begin{array}{l}\text { Up to } \\
300\end{array}$ & Up to 350 \\
\hline \multirow{2}{*}{$\begin{array}{l}\text { (GC,BC,R } \\
\text { C) }\end{array}$} & Old & 3 & $\begin{array}{l}\text { Up to } \\
15\end{array}$ & Up to 15 & Up to 15 \\
\hline & New & 3 & $\begin{array}{l}\text { Up to } \\
160\end{array}$ & $\begin{array}{l}\text { Up to } \\
225\end{array}$ & Up to 270 \\
\hline
\end{tabular}

In addition to the private sector, authorities and government agencies are involved in construction of infrastructures by employing in-house advisors. As a result, a considerable number of expertises have been employed. Nevertheless, the

2www.MoUDHC.gov.etaccessed on March , 2015. construction work performance in building construction does not progress as it is supposed to be, for the last 50 years.

\subsection{Hypothesis}

Hypothesis 1:

$\mathrm{HO}=$ There is no association between the response of the contractors and consultants for cost overrun factors.

$\mathrm{H} 1=$ There is an association between the response of the contractors and consultants for cost overrun factors.

Hypothesis 2:

$\mathrm{H} 0=$ There is no association between the response of the contractors and clients for cost overrun factors.

$\mathrm{H} 1=$ There is an association between the response of the contractors and clients for cost overrun factors.

Hypothesis 3:

$\mathrm{H} 0=$ There is no association between the response of the consultants and clients for cost overrun factors.

$\mathrm{H} 1=$ There is an association between the response of the consultants and clients for cost overrun factors.

\section{Related Literatures}

Completion of a construction project with intended budget is frequently seen as a major criterion of project success by clients, contractors, consultants and related stakeholders. It is here that project management becomes essential tool for the delivery of effective projects than the traditional functional management. The Project Management Institute Project Management Body of Knowledge (PMBoK) Guide defines a project as "a temporary endeavor undertaken to create a unique product or service" (PMI, 1996).

Project Management Constraint 1: Cost Overrun and Mitigation Measures

Cost in a project comprises money and resources (people, equipment, and materials). The client usually wants the project to be finished with the possible lowest cost and timely. However, it is the project manager's responsibility to adopt or formulate a performance standard to track cost performance (Larry, 2002). Several factors that cause cost overruns in construction projects have been identified in various places and time. The basic reason for cost overrun is that most contractors quote price based on their projected estimates. Unfortunately, the price change so quickly that the initial budget become completely unrealistic (Azhar et al, 2008). According to Larry, (2002) project cost is influenced by the following factors: specifications of the end products (such as levels of performance, quality, and reliability); compliance with governmental, institutional, or internal standards; and technical requirements (such as a need to upgrade computer hardware) and administrative needs (such as a company's financial policies). Chabota et al., (2008) discussed that the major causes of cost escalation in Zambia's road construction are bad or inclement weather due to heavy rains and floods, scope changes, environmental protection and mitigation costs, schedule delay, strikes, technical challenges, inflation and local government pressures. In his survey, among 60 participants, $(73 \%)$ indicated that the causes of cost escalation 
are bad weather, $(63 \%)$ indicated the cause as scope changes, $(61 \%)$ indicated the cause as environmental protection and mitigation cost, (54\%) indicated the cause as schedule delay, $(52 \%)$ indicated the cause as strikes and the remaining $50 \%$ indicated that the causes of cost escalation are local government pressures, technical challenges and inflation.

Similar study by Luka, (2014) conducted in Nigeria with fifty eight (58) respondents who are all construction professionals, revealed that the average impact of cost related risks with standard deviation are associated with the following five factors: incomplete or inaccurate cost estimate $(0.5886 \pm 0.2948)$, inadequate program planning $(0.5257 \pm 0.1821)$, variation by client $(0.4914 \pm 0.2077)$, design variation $(0.4743 \pm 0.2063)$, and price inflation $(0.4514 \pm 0.2241)$. The average impacts of these factors represent the degree of potential loss on construction project cost in the construction industry. Another study conducted in Malaysia by Ali and Kamaruzzaman, (2010) on 30 respondents from construction firms, shows that cost overrun becomes critical issue in Malaysia construction and ranked 13 factors contributed to cost overrun. These 13 factors in descending order are the following: inaccurate/ poor estimation of original cost, construction cost underestimation, improper planning, poor project management, lack of experience, poor contract management, inflation of project costs, high cost of machineries, fluctuation in price of raw materials, unforeseen site conditions, insufficient fund, obsolete / unsuitable construction equipment and methods, and mistake in design.

Based on their findings, Ali and Kamaruzzaman, (2010) ranked the following 11 measures in descending order to control construction cost: proper project costing and financing, proper cost control competent personnel, efficient management, risk management during project execution, realistic cost estimation, appropriate scope definition, appropriate contractual framework, establish training programs, increase supply of materials, and establish a system in design. A study made among 26 consultants using questionnaire in Palestinian building construction projects by Ibrahim and Nabil, (2013), revealed a 100\% cost overrun. The responses indicated average cost overrun between $10 \%$ and $30 \%$ of the project's estimated cost. The study identified 41 cost overrun factors, of which 26 are critical ones. The top five factors prioritized by the consultants affecting cost overrun in building construction projects are: political situation, fluctuation of materials price, level of competitors, currency exchange, and economic instability. The researchers suggested the following mitigation measures for the above discussed cost overrun factors: Training courses and workshops, provision of updated Material price and labor rates, provision of sufficient time for tender submission, on time payment, communication and coordination among project staffs and top management reaction to political and environmental issues. Similar study conducted in Palestine by Mahamid and Amund, (2012) among a sample of 169 road construction projects, $100 \%$ of the projects suffer from cost deviation: $76 \%$ of the projects are under-estimated cost while the rest $24 \%$ of the projects are over- estimated.

Olawale and Sun, (2010) performed a study on 150 construction companies, 100 consultants on construction project organizations in the UK, which was also followed by face-to-face interviews with 15 experienced practitioners. In the study, a list of 20 factors were used for identifying project cost and time control inhibiting factors: inflation of prices, fluctuation of currency/exchange rate, unstable government policies, weak regulation and control, unpredictable weather conditions, dependency on imported materials, low skilled manpower, risk and uncertainty associated with projects, unstable interest rate, lack of proper training and experience of pm, lack of appropriate software, inaccurate evaluation of projects time/duration, non-performance of subcontractors and nominated suppliers, project fraud and corruption, design changes, financing and payment for completed works, complexity of works, discrepancies in contract documentation, contract and specification interpretation disagreement and conflict between project parties. Accordingly, the top five factors identified in inhibiting effective project cost control in descending order are: Design changes, Risk and uncertainty associated with projects, inaccurate evaluation of projects time/duration, Nonperformance of subcontractors and nominated suppliers and complexity of works. The first factor of design change is very critical and needs carful management. These top five factors were considered for suggesting mitigating measure and accordingly 90 mitigating measures of preventive, predictive, corrective and organizational natures were derived by making intensive literature review and face to face discussion with 15 participants (Olawale and Sun, 2010).

In Ethiopia, a study conducted by Nega, (2008) on predominant factors for cost overrun in public building construction projects in Ethiopia are identified the following major cost overrun factors. These are inflation or increase in the cost of construction materials, poor planning and coordination, change orders due to enhancement required by clients, and excess quantity during construction.

A study made on project management maturity in the Ethiopian construction industry by Abadir, (2011) found out that $22 \%, 22 \%, 22 \%$ and $28 \%$ of the contractors cost management process maturity is incomplete, perform informally, perform formally and managed well, respectively. Whereas, the cost management practice maturity is $10 \%, 48 \%$, $38 \%$ and $5 \%$ apply no practice, incomplete, basic and intermediate, respectively. His study pointed out that $90 \%$ of the contractors prepare detailed estimate of cost of labor, material and machinery. However, only $75 \%$ prepare detailed budget, about $70 \%$ track cost of labor, material and machinery separately, and $67 \%$ collect and use company's historical data for preparation of cost estimate. His study further indicate that only $1 / 3$ of the contractors use computer tools for cost estimate preparation and about $2 / 3$ update their budget regularly at least once in a month. The contractors perform formal financial management process.

Harold, (2009) stated that in the 1980s the failure of a project was largely a quantitative failure due to ineffective planning, scheduling, estimating, and cost control. As a result 
project objectives had become a moving object. In effective project management in small organizations (1 to 30 million dollar projects), manual may be acceptable rather than computerized cost control.

Cost management is among the very important dimension of project management. The Earned Value Analysis (EVA) is a cost management tool that is used to evaluate cost performance of different types of projects.

\section{Research Design and Methodology}

\subsection{Description of the Study Area}

Ethiopia is located in the horn of Africa. It covers an area of about 1.13 million square kilometers and the topography of the country is rugged ranging with an altitude from $125 \mathrm{~m}$ below sea level to $4,620 \mathrm{~m}$ above sea level. The country has an elevated central plateau varying between 2,000 and 3,000 meters above sea level (Figure 1).

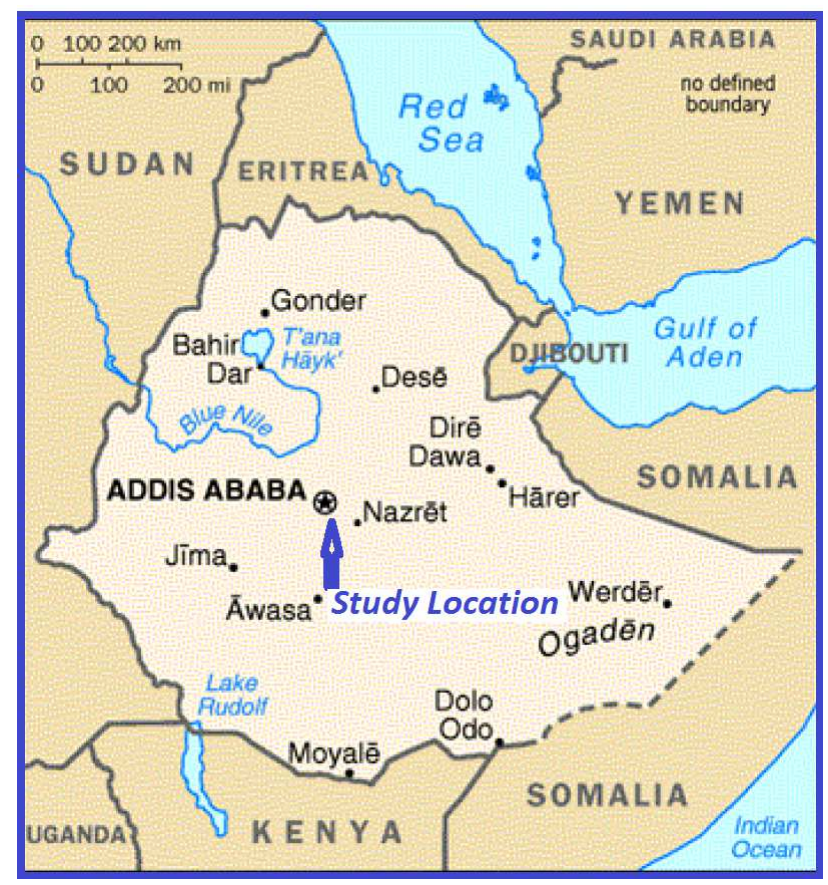

Figure 1. Map of Ethiopia.

\subsection{Sampling Methods and Sample Size}

Considering the homogeneity of the construction sector from grade one to three in terms of formulation and category, convenient sampling was adopted for preliminary and final questionnaire distribution. Convenient sampling was used due to the fact that the sensitivity of the question types and needs some follow-up and further push to get reliable response and to have high number of return of the questioners.

Among the most important element of the research, the sample size is the one which addresses the characteristics of the whole file series with confidence. To stick with good statistical validity, the study made use of a representative sample size. For this study maximum care is given to get the highest sample size (OSP, 2005). For the study the numbers of grade one to three contractors are 499 and accordingly the sample size determined based on Table 3 and found out the sample size of 80 .

The consultant and contractors who had worked with the selected contractors were asked to respond to similar questioners using quota sampling.

According to the formula used to determine the sample size by Yamane (1967),

$$
n_{0}=\frac{z^{2} p(1-p) N}{z^{2} p(1-p)+N e^{2}}
$$

Where:

no $=$ sample size

$\mathrm{z}=$ confidence interval corresponding to a level of confidence

$\mathrm{p}=$ population proportion

$\mathrm{N}=$ population size

$\mathrm{e}=$ precision or error limit

Taking the value of $\mathrm{N}=499$, which is the total size of the population (Grade one to three contractor), $Z=1.96(95 \%$ Confidence Interval), $\mathrm{p}=0.5$ and level precession $\mathrm{e}=10 \%$, the required sample size found were 80 .

Again, taking Yamane (1967) formula for determining the required response rate for the amount of sample size determined, the researcher used the below method of determination.

$$
r=\frac{n}{1+n e^{2}}
$$

Where:

$\mathrm{n}=$ sample size

$\mathrm{r}=$ required responses

$\mathrm{e}^{2}=$ error limit or the level of precision) $10 \%$

Accordingly, by assuming response rate of $56 \%$ the sample size to be distributed was identified as 130 for the contractors and finally able to achieve $75.4 \%$ of response rate.

Table 3. Sample size determination.

\begin{tabular}{llll}
\hline \multicolumn{1}{c}{${ }^{1}$} & Sample Size & & \\
\hline & Low & Medium & High \\
$51-90$ & 5 & 13 & 20 \\
$91-150$ & 8 & 20 & 32 \\
$151-280$ & 13 & 32 & 50 \\
$281-500$ & 20 & 50 & 80 \\
$501-1,200$ & 32 & 80 & 125 \\
$1,201-3,200$ & 50 & 125 & 200 \\
$3,201-10,000$ & 80 & 200 & 315 \\
$10,001-35,000$ & 125 & 315 & 500 \\
$35,001-150,000$ & 200 & 500 & 800 \\
\hline
\end{tabular}

Source: J Carvalho, "Archival application of mathematical sampling techniques", Records Management Quarterly 18:63 (1984) as cited on OSPO, 2005 .

\subsection{Validity and Reliability}

Reliability and validity in quantitative research reveal two strands: Firstly with regards to reliability, whether the result is 
replicable and with regards to validity, whether the means of measurement are accurate and whether they are actually measuring what they are intended to measure (Nahid, 2003).

Kirk and Miller (cited in Nahid, 2003) identify three types of reliability referred to in quantitative research, which relate to: 1) the degree to which a measurement, given repeatedly, remains the same, 2) the stability of a measurement over time, 3 ) the similarity of measurements within a given time period.

The questionnaire was reliable in that it used the same questions to all respondents and was answered in similar ways. The questions were adopted from previously done studies which were subject to critics and the content validity was addressed in that all questions clearly represented all the variables intended to measure for the desired objective of showing the impacts of the independent variables on the dependent variable.

\subsection{Data type, Sources, and Methods of Data Collection}

Both quantitative and qualitative methods were used: in step one qualitative analysis were done for identifying factors from literature and checked on selected respondents; in step two quantitative data were collected using questionnaire (Figure 2). This study involved largely the use of primary data for the purpose of empirical analysis. The primary data were obtained with the use of structured questionnaires and selected interviews. Secondary data were used for preparation of the questioner and to discuss the findings of the research.

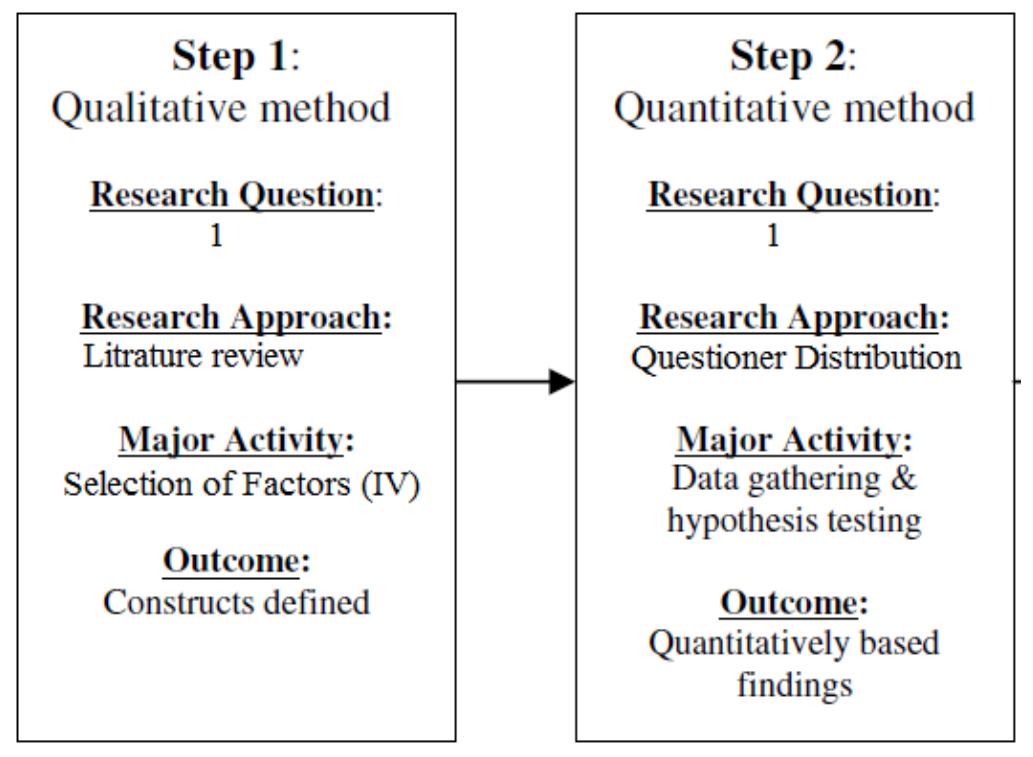

Figure 2. The two step approach for this research.

\section{Part one: Questionnaire Survey}

For the survey, pretested questionnaire was developed to assess factors for cost overrun perception. Preliminary questionnaires were sent to 10 professionals for their comment and adjustment. Their comments and inputs were incorporated in development of the final questionnaire that was distributed and collected.

The list of contractors was first obtained from online archive. Online search was further conducted to identify their contact address and detail. The questionnaires were sent to different organizations via their email. Moreover, personal contacts with senior professionals in the field were used to gather data and also to link to other potential respondents. When linked to professionals through personal contacts, the name of the construction company was recorded and appropriate follow up was done to make sure that the questionnaire was filled by the appropriate professional and to ensure a good questionnaire response rate.

Respondents of the questionnaire consists of Grade one to three Building contractor (BC)/ General contractor (GC), road contractors (RC) of governmental as well non-governmental bodies; consultants and clients. The survey enabled the respondents to identify the challenge in the construction field regarding cost. The model in the questionnaire cost overrun factor was identified by conducting detailed literature review (Luka, 2014; Ibrahim and Nabil, 2013; Mahamid and Amund, 2012; Abadir, 2011; Ali and Kamaruzzaman, 2010; Olawale and Sun, 2010; Azhar et al, 2008; Chabota et al., 2008 and Nega, 2008). Accordingly, different factors were tabulated in to a questionnaire (Table 3 ).

The questions were structured in such a way as to provide pertinent information on the extent of cost variation on projects. These questions were made simple and straight forward in order to ensure maximum responses from the respondents. For the questionnaire, Likert scale of " $1=$ very little; $2=$ little; $3=$ moderate; $4=$ high and 5= very high" were used.

The questionnaire distributed had two sections:

- Section I gathers basic background information about the particular respondent. It includes questions asking the type of organization, position, salary, educational level, year of experience etc.

- Section II consists of 41 cost overrun factors whereby respondents were expected to rate based on their importance. The causes of cost overrun of contractors study was made by classifying 41 factors in to five broad 
categories (cost estimation factor, construction items, project participants, environmental and financial) for mutual exclusivity.

The questionnaires, along with the cover letter, were distributed to the concerned company employee either in hard or soft copies whichever was convenient. Physical visits and/or intensive telephone conversations were made to all the respondents. The purpose of the communication was to clarify some of the points found vague to the respondents in the questionnaires, to follow up the responses, and to collect filled ones. Respondents were assured that their responses would be kept confidential.

\subsection{Data Analysis}

The data collected through pre-tested structured questionnaire were categorized and analyzed. Content analysis was further employed in the presentation of the results. The data were tabulated, analyzed and interpreted using SPSS (version 20). The five-point scale was converted to a Relative Importance Index (RII) for each individual factor using the following formula(Luka, 2014; Ibrahim and Nabil, 2013; Mahamid and Amund, 2012; Abadir, 2011; Olawale and Sun, 2010; Azhar et al, 2008; Chabota et al., 2008 and Nega, 2008):

Relative importance index $(\mathrm{RII})=\Sigma \mathrm{W} \div(\mathrm{H} \mathrm{x} \mathrm{N})$

Where $\mathrm{w}$ is the total weight given to each factor by the respondents, which ranges from 1 to 5 and is calculated by an addition of the various weightings given to a factor by the entire respondent, $\mathrm{H}$ is the highest ranking available (i.e. 5 in this case) and $\mathrm{N}$ is the total number of respondents that have answered the question.

Finally, an statistical test was conducted on cost control ranking agreement or disagreement of the respondents (contractor, consultant and client) with the help of spearman rank correlation coefficient. Where, the Spearman's rank correlation is a non-parametric test correlation varies between +1 and -1 , where +1 signifies perfect positive correlation and -1 show a perfect negative correlation or disagreement. Correlation coefficient value of \pm 1 is said to be a perfect correlation. In this study, we assume that a value lying between \pm 0.5 and \pm 1 reflects a high degree of correlation, a value lying between \pm 0.3 and \pm 0.5 reflects a moderate degree of correlation, while a value lying between \pm 0.1 and \pm 0.3 reflects a low degree of correlation. It is possible to reject the null hypothesis, when the absolute value of the obtained $\rho$ is larger than the critical $\rho$ (.254 for P.01) for $\mathrm{N}=98$.

A correlation coefficient value lying around zero means that there is no correlation.

Spearman rank correlation formula:

$$
\mathrm{rs}=1-\left(6 \Sigma \mathrm{di}^{2} /\left(\mathrm{N}^{3}-\mathrm{N}\right)\right) .
$$

Where, $r_{s}$ is the Spearman rank correlation coefficient, $d_{i}$ represents the difference between ranks for each case and $\mathrm{N}$ is the number of subjects or pairs of ranks (Weinberg and Abromowitz, 2008; Cohen, 1988).

For $\mathrm{N}>30$, the critical value from Spearman's $(\mathrm{N}=30, \mathrm{p}$ $=.05)=.363$ "close enough"
Table 4. List of cost overrun factors.

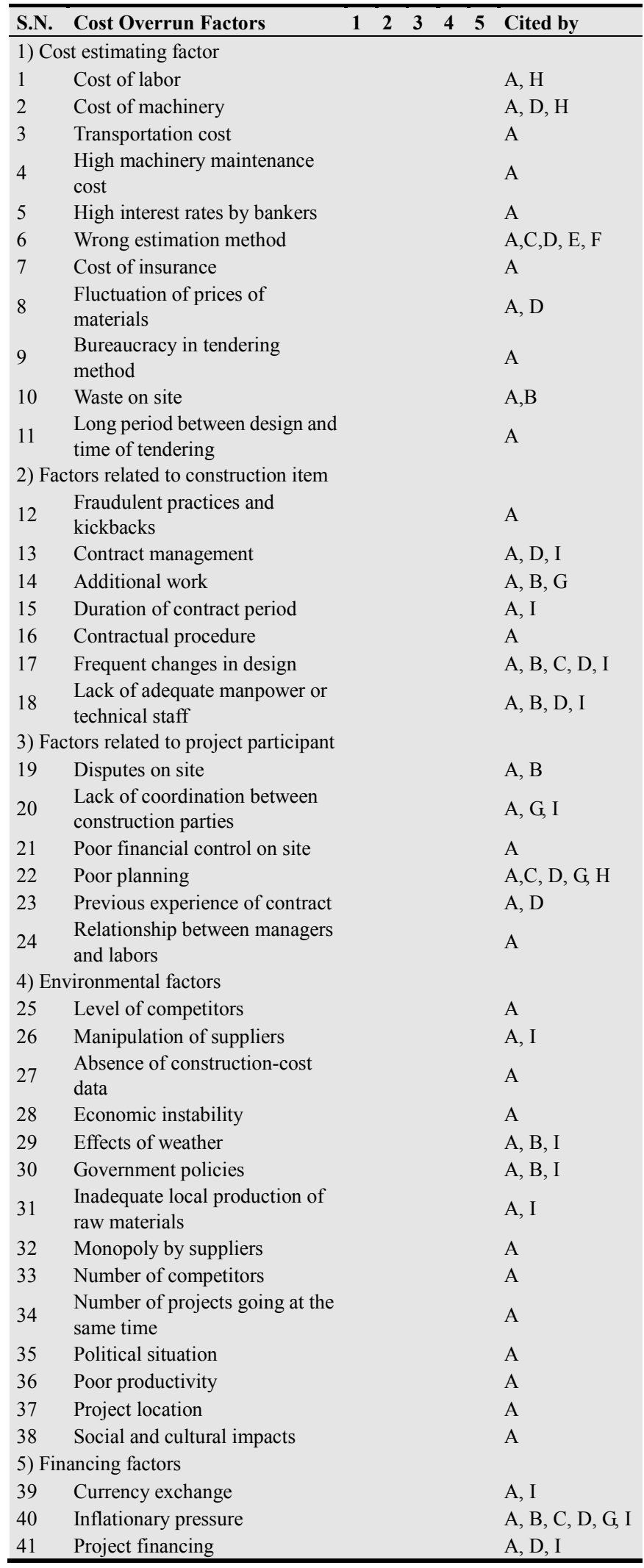

$1=$ very little; $2=$ little; $3=$ moderate; $4=$ high and $5=$ very high

A (Ibrahim and Nabil, 2013); B (Chabota et al., 2008); C (Luka, 2014); D (Ali and Kamaruzzaman, 2010); E (Azhar et al, 2008); F (Mahamid and Amund, 2012); G (Nega, 2008); H (Abadir, 2011); I (Olawale and Sun, 2010); 


\section{Result and Discussion}

\subsection{Demographic}

The structured questionnaire survey is designed to determine the major causes of cost variation in construction projects in Ethiopia. 140 participants were questioned in the survey. The respondents are categorized into three groups, namely contractors, consultants and clients which, of course, are implementing agencies and financiers. The response rate for the questionnaire survey for the above mentioned contractors, consultants and clients are $75.4 \%, 43.3 \%$ and $40.0 \%$, respectively (Table 5). According to Sekaran (2001), a response rate of $30 \%$ is acceptable for most studies; therefore, as the response rate of this study is more than what is referred as adequate by Sekaran (2001), the response rate is measured as adequate for the study.

Table 5. Response Rate for the Structured Questioner.

\begin{tabular}{lllll}
\hline Group & Distributed & Returned & Valid & $\begin{array}{l}\text { Valid among } \\
\text { distributed in } \\
\text { percentage }\end{array}$ \\
\hline Contractors & 130 & 104 & 98 & 75.4 \\
Consultants & 60 & 33 & 26 & 43.3 \\
Clients & 40 & 24 & 16 & 40.0 \\
\hline
\end{tabular}

Profile of questionnaire respondents

The academic qualifications of the respondents were assessed. Accordingly, out of 140 participants 18, 78 and 44 of the respondents have diploma, bachelor and Masters Degree in engineering, respectively. The education qualifications of the respondents suggest sufficient educational qualification to make the information acquired reliable (Figure 3).

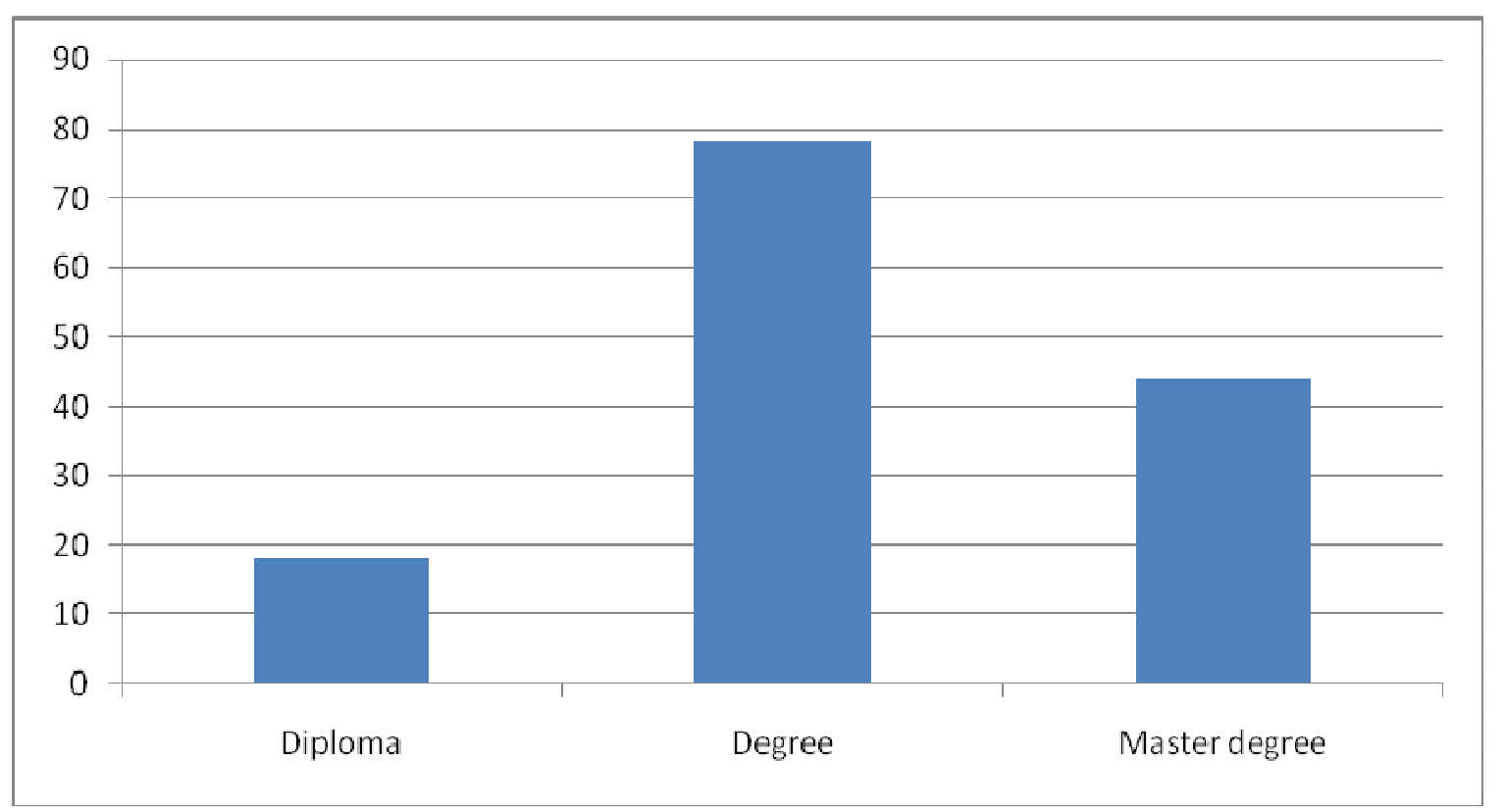

Figure 3. Academic Qualifications of Total Respondents.

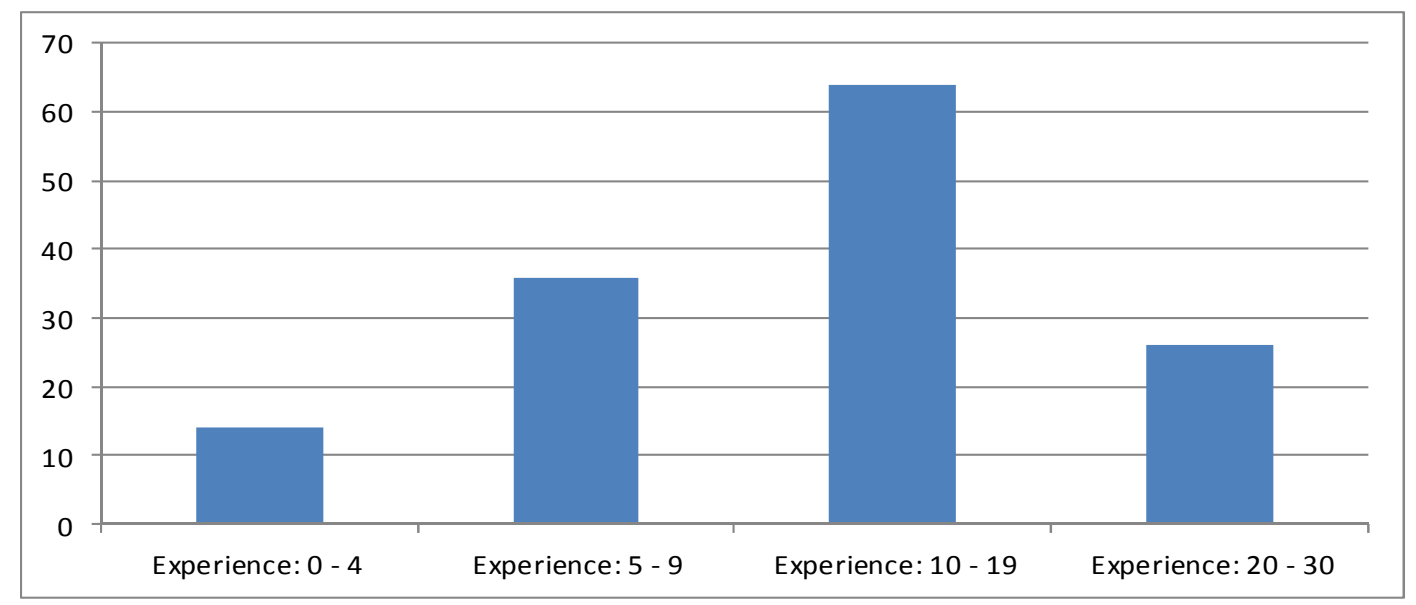

Figure 4. Working Experience of the Total Respondents.

As per the survey, out of the total 140 respondents 60,46 , 26 and 6 of the respondents have experience in their current company from 0 to 4,5 to 9,10 to 19 and 20 to 30 , respectively (Figure 4). 
Table 6. Contractors Response for Cost Overrun Factors.

\begin{tabular}{|c|c|c|}
\hline No. & Contractors Response of Cost Overrun Factors & Mean \\
\hline 1 & Poor planning & 3.918 \\
\hline 2 & Fluctuation of prices of materials & 3.918 \\
\hline 3 & Poor productivity & 3.714 \\
\hline 4 & Inflationary pressure & 3.673 \\
\hline 5 & Project financing & 3.612 \\
\hline 6 & Duration of contract period & 3.571 \\
\hline 7 & Poor financial control on site & 3.551 \\
\hline 8 & Monopoly by suppliers & 3.469 \\
\hline 9 & Contract management & 3.469 \\
\hline 10 & Cost of machinery & 3.408 \\
\hline 11 & Inadequate local production of raw materials & 3.408 \\
\hline 12 & Bureaucracy in tendering method & 3.388 \\
\hline 13 & Currency exchange & 3.347 \\
\hline 14 & High machinery maintenance cost & 3.327 \\
\hline 15 & Lack of adequate manpower or technical staff & 3.327 \\
\hline 16 & Number of projects going at the same time & 3.306 \\
\hline 17 & Wrong estimation method & 3.306 \\
\hline 18 & Number of competitors & 3.265 \\
\hline 19 & High interest rates by bankers & 3.224 \\
\hline 20 & Absence of construction-cost data & 3.204 \\
\hline 21 & Transportation cost & 3.163 \\
\hline 22 & Previous experience of contract & 3.163 \\
\hline 23 & Manipulation of suppliers & 3.143 \\
\hline 24 & Cost of labor & 3.122 \\
\hline 25 & Lack of coordination between construction parties & 3.102 \\
\hline 26 & Economic instability & 3.102 \\
\hline 27 & Contractual procedure & 3.082 \\
\hline 28 & Fraudulent practices and kickbacks & 3.082 \\
\hline 29 & Waste on site & 3.061 \\
\hline 30 & Project location & 3.041 \\
\hline 31 & Frequent changes in design & 3.020 \\
\hline 32 & Long period between design and time of tendering & 3.000 \\
\hline 33 & Additional work & 2.959 \\
\hline 34 & Government policies & 2.959 \\
\hline 35 & Relationship between managers and labors & 2.837 \\
\hline 36 & Effects of weather & 2.796 \\
\hline 37 & Level of competitors & 2.735 \\
\hline 38 & Social and cultural impacts & 2.653 \\
\hline 39 & Disputes on site & 2.531 \\
\hline 40 & Cost of insurance & 2.531 \\
\hline 41 & Political situation & 2.122 \\
\hline
\end{tabular}

Then again, out of the total 140 respondents, 14, 36, 64 and 26 of the respondents have the following total experience in the construction industry from 0 to 4,5 to 9,10 to 19 and 20 to
30 , respectively. The profile and experience of the respondents suggest sufficient exposure to make the information acquired reliable.

\subsection{Cost Overrun Factors}

After identifying from literature different factors that result in cost overrun of construction projects, questioner was prepared, incorporating 41 factors and the responses are ranked in Table 6. As per the contractors' response top five factors that causes cost overrun of construction projects are identified. These factors are poor planning (3.918), fluctuation of prices of materials (3.918), poor productivity (3.714), inflationary pressure (3.673) and project financing (3.612) (Figure 5). All the factors are ranked from medium to high; this could be linked to lower acceptances of the fact and/or high debate on the factors. On the other hand, the top 5 factors as per the response of consultants and clients are ranged between high to very high (Annex-A, Table 8).

Poor Planning

The contractors claimed that out of 41 factors, poor or inappropriate planning is the first factor which contributes to cost overrun of projects. The response of the consultants and the clients ranked as $1^{\text {st }}$ level with mean value of 4.231 and 4.500 , respectively. This shows the need for improving the planning; this can be improved with the application of training, techniques and software. In line with this, Luka, (2014) investigated the construction cost overrun in Nigeria due to inadequate planning which is ranked as $2^{\text {nd }}$. Olawale and Sun, (2010) also showed construction projects in the UK and found out that out of 20 factors the $4^{\text {th }}$ ranked factor is inaccurate evaluation of projects duration. Ali and Kamaruzzaman, (2010) as well showed Malaysian construction projects cost overrun due to poor planning which is ranked as $2^{\text {nd }}$. Nega (2008) also showed the cost overrun in public construction projects in Ethiopia as mainly due to poor planning.

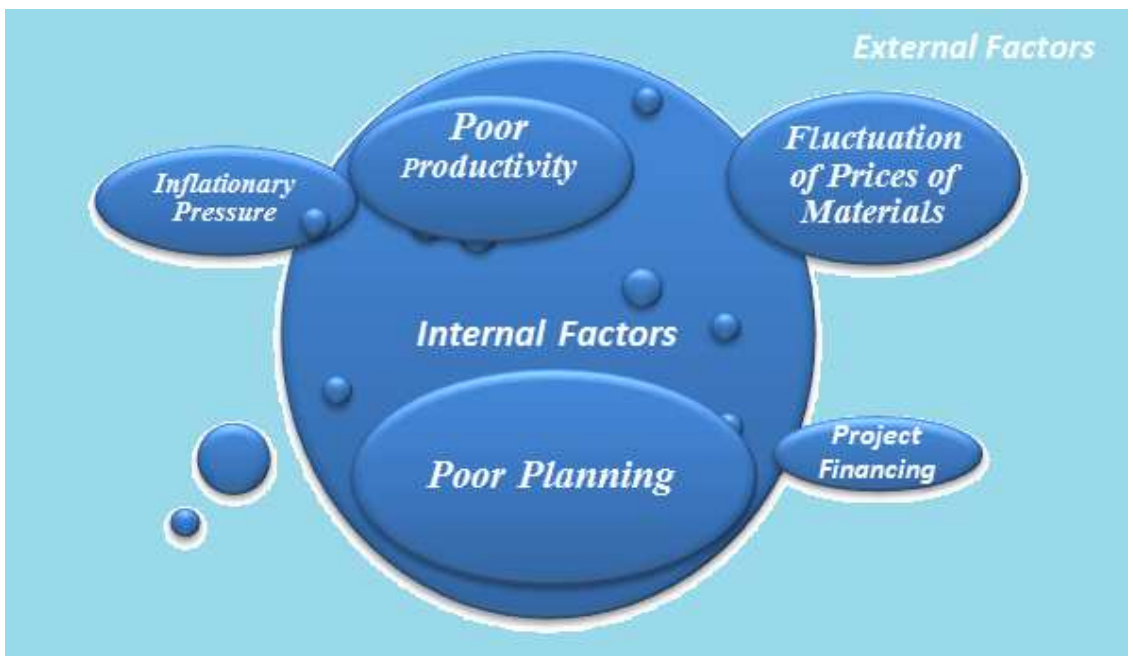

Figure 5. Top Five Internal and External Factors Affecting Cost Overrun in Ethiopian Construction Sector. 
Price Fluctuation of Materials

The contractors' rank of price fluctuation of materials (3.918) during construction as the $1^{\text {st }}$ problem is comparable with the responses by the consultants and clients (Annex-A, Table 1). Where, the consultants and clients ranked it as $2^{\text {nd }}$ and $3^{\text {rd }}$ factor for the cause of cost overrun with a mean of 4.154 and 4.000, respectively. Improvement in planning can also results in a better understanding level of material price fluctuation regardless of the fact that the situation is partially external and difficult to manage. This could be due to the booming constructions and contractors number in the country. One way to resolve this could be by increasing supply of materials.

In agreement with this, Ali and Kamaruzzaman, (2010) showed Malaysian construction projects cost overrun due to price fluctuation of raw materials which is ranked as $9^{\text {th }}$ out of 13 cost overrun factors and recommends increasing materials supply. Ibrahim and Nabil, (2013) who study in Palestine building construction, also showed that price fluctuation of materials is the $2^{\text {nd }}$ out of 41 cost overrun factors. The basic reason of cost overruns as quoted by most contractors is prices based estimates, and unfortunately, the price change so quickly that the initial budget figure becomes completely unrealistic (Azhar et al, 2008). Nega (2008) has also showed that the cost overrun in public construction projects in Ethiopia is primarily due to increase in cost of construction materials.

Poor Productivity

The contractors ranked the poor productivity as a $3^{\text {rd }}$ factor which results in cost overrun. This is comparable with the responses of the consultants and clients which are $4^{\text {th }}(4.000)$ and $2^{\text {nd }}(4.125)$ out of 41 cost overrun factors, respectively. This could be improved by the adoption of proper planning techniques and methods for project evaluation and monitoring.

Inflationary Pressure

The contractors' ranked inflation as a $4^{\text {th }}$ factor which results in cost overrun. The consultants and clients also ranked inflation as $9^{\text {th }}(3.846)$ and $25^{\text {th }}(3.25)$ which shows the clients difference; instead, the clients pointed out other factors such as lack of adequate manpower or educated staffs, project location etc as a primary cost overrun factor. It is witnessed that the aggressive move of the country towards the achievement of its target to become a middle income country by the year 2025 could be realized at the expense of inflation $^{3}$, and the response of the contractors is the same as the above mentioned statement. The result of inflation could be the main reason for the materials price fluctuation.

In line with this finding, Chabota et al., (2008) stated that among the major causes of cost escalation in Zambia's road construction, the $5^{\text {th }}$ ranked factor is local government pressures, technical challenges and inflation which all scored $50 \%$. Luka, (2014) also investigated the construction cost overrun in Nigeria, and find out that price inflation is ranked

${ }^{3}$ www.foreignaffairs.com/ethiopia-sponsored-section as the $5^{\text {th }}$ factor. Ali and Kamaruzzaman, (2010) also showed Malaysian construction projects cost overrun caused by inflation is ranked as $7^{\text {th }}$ out of 13 cost overrun factors. Ibrahim and Nabil, (2013) study in Palestine building construction showed that currency exchange and economic instability are the $4^{\text {th }}$ and $5^{\text {th }}$ cost overrun factors out of 41 factors. Nega (2008) as well showed the cost overrun in public construction projects in Ethiopia is primarily due to inflationary pressure.

Project Financing

The contractors ranked project financing as a $5^{\text {th }}$ cost overrun factor. This is unlike the responses of the consultants and clients as who ranked $25^{\text {th }}(3.462)$ and $36^{\text {th }}(2.500)$, respectively. It is a fact that one way or the other when cases like delay in payment happens the contractors incur additional costs and/or results in delay of project which in return result cost overrun. Hence, the provision of alternative mechanisms such as availability of working capital and others can be a way out. In line with this, Ali and Kamaruzzaman, (2010) showed Malaysian construction projects cost overrun caused by insufficient fund is ranked as $11^{\text {th }}$ out of 13 cost overrun factors. Ali and Kamaruzzaman, (2010) recommend out of the 11 factors the arrangement of proper project costing and financing should be the $1^{\text {st }}$ for success of project.

The selected top five cost overrun factors can be categorized as internal and external as shown in Figure 5. According to $\mathrm{PMBOK}$, project can be finalized within approved budget if project cost management incorporating the three steps of estimating, budgeting and controlling costs is managed well. Accordingly, the implementation of effective project cost management can eliminate or reduce poor planning as well poor productivity (Harold, 2009).

However, the effect of price fluctuation of materials and project financing can be managed by both the contractor and the support from the stakeholders. The contractor can minimize price fluctuation of materials by holding stock. The client or government can increase supply and/or consider some price adjustment. The inflationary pressure is out of the contractor's control; and, it should be considered by the regulatory body to have some room for compensation.

\subsection{Hypotheses Testing Results for Cost Overrun Factors}

For the assessment of correlation between contractors, consultants and clients of cost overrun ranked factors, the hypotheses checkup is as follow:

Table 7. Cost Overrun Factors Response Correlations between Contractors, Consultants and Clients (Spearman rank correlation, $r$ ).

\begin{tabular}{llll}
\hline & Contractors & Consultants & Clients \\
\hline Contractors & 1 & 0.674 & 0.466 \\
Consultants & 0.674 & 1 & 0.573 \\
Clients & 0.466 & 0.573 & 1 \\
\hline
\end{tabular}


Hypothesis 1:

$\mathrm{H} 0=$ There is no association between the responses of the contractors and consultants for cost overrun factors.

$\mathrm{H} 1=$ There is an association between the responses of the contractors and consultants for cost overrun factors.

Results displayed in table 7 above, $r=0.674$, showed the response correlation between contractors and consultants. As Weinberg and Abromowitz, (2008) explained, the correlation coefficient is a number between -1 and 1 that determines whether two paired sets of data are related and the closer to 1 , the more confident we are of a positive linear correlation and the closer to -1 , the more confident we are of a negative linear correlation. From the above stated facts, it can be seen that the null hypothesis is rejected and H1 is accepted by showing high correlation.

Hypothesis 2:

$\mathrm{H} 0=$ There is no association between the responses of the contractors and clients for cost overrun factors.

$\mathrm{H} 1=$ There is an association between the responses of the contractors and clients for cost overrun factors.

From the result displayed in table 7 above, where $r=0.466$, which shows the existence of positive linear correlation. As a result, the null hypothesis is rejected and $\mathrm{H} 1$ is accepted by showing medium correlation.

Hypothesis 3:

$\mathrm{H} 0=$ There is no association between the responses of the consultants and clients for cost overrun factors.

$\mathrm{H} 1=$ There is an association between the responses of the consultants and clients for cost overrun factors.

As displayed in table 7 above, where $r=0.573$, which shows the existence of positive linear correlation. As a result, the null hypothesis is rejected and $\mathrm{H} 1$ is accepted by showing high correlation.

The result of spearman coefficient between contractors and clients, clients and consultants, and contractors and consultants are $0.47,0.57$, and 0.67 , respectively. The result of spearman rank correlation coefficient for cost overrun shows a higher correlation between contractors and consultants since they are the ones who have a direct burden of the day to day routine work. The medium correlation between the contractors and clients could be due to conflict of interest on cost overrun. The result shows that the consultants impartial view on the differences among the clients and contractors. Within the construction administration, the consultants might be seen as more favorable towards the clients; however, the result of this finding shows that the consultants have no interest of taking side.

\section{Summary, Conclusion and Recommendations}

This chapter deals with the summary of findings, conclusions and recommendations. As per the contractor' response, the top five factors that causes cost overrun of construction projects were from medium to high. On the other hand, the top 5 factors as per the response of consultants and clients ranged between high to very high. The contractors outlined the top five factors that causes in cost overrun of construction projects are poor planning, fluctuation of price of materials, poor productivity, inflationary pressure and project financing in descending order.

Similarly, the top five cost overrun can be monitored by cooperation among project stakeholders to create efficient project success. The results of spearman coefficient for cost overrun factor ranking of construction project between contractors and clients, clients and consultants, and contractors and consultants are $0.47,0.57$, and 0.67 respectively showing very good correlation.

The study bases the current environment of the construction industry, however the construction industry changes so fast. Thus, in the future, the investigation of factors result in cost overrun may be maintained constantly with their mitigation measures. To conduct research in different countries in order to grasp a more global view of cost overrun factors in construction companies in practice may be determined. Applying the same study criteria to other countries could be examined. One could use some of this study's ideas but focus specifically on projects that experienced significant cost overrun. Further study of ranking the survey responses by profession and by sector would result interesting findings. Study based on project size and duration would result interesting findings.

\section{Annex A}

Table 8. Response of Cost Overrun Factors by Consultants and Clients.

\begin{tabular}{llll|}
\hline No. & Consultant reply of Cost Overrun & Mean & Client reply of Cost Overrun Factors \\
\hline 1 & Poor planning & 4.231 & Poor planning \\
2 & Fluctuation of prices of materials & 4.154 & Poor productivity \\
3 & Inadequate local production of raw materials & 4.077 & Fluctuation of prices of materials \\
4 & Poor productivity & 4.000 & Lack of adequate manpower or technical staff \\
5 & Lack of adequate manpower or technical staff & 4.000 & Project location \\
6 & Poor financial control on site & 3.923 & Monopoly by suppliers \\
7 & Economic instability & 3.846 & Poor financial control on site \\
8 & Monopoly by suppliers & 3.846 & Cost of machinery \\
9 & Inflationary pressure & 3.846 & Transportation cost \\
10 & Cost of machinery & 3.769 & Long period between design and time of tendering \\
\hline
\end{tabular}




\begin{tabular}{|c|c|c|c|c|}
\hline No. & Consultant reply of Cost Overrun & Mean & Client reply of Cost Overrun Factors & Mean \\
\hline 11 & Waste on site & 3.769 & Frequent changes in design & 3.625 \\
\hline 12 & Contract management & 3.769 & Lack of coordination between construction parties & 3.625 \\
\hline 13 & Currency exchange & 3.769 & Inadequate local production of raw materials & 3.625 \\
\hline 14 & Long period between design and time of tendering & 3.692 & Currency exchange & 3.625 \\
\hline 15 & Additional work & 3.692 & Cost of labor & 3.500 \\
\hline 16 & Number of projects going at the same time & 3.692 & Duration of contract period & 3.500 \\
\hline 17 & Absence of construction-cost data & 3.692 & Social and cultural impacts & 3.500 \\
\hline 18 & Manipulation of suppliers & 3.615 & Contract management & 3.375 \\
\hline 19 & Transportation cost & 3.615 & Additional work & 3.375 \\
\hline 20 & Duration of contract period & 3.615 & Number of competitors & 3.375 \\
\hline 21 & Lack of coordination between construction parties & 3.538 & Contractual procedure & 3.250 \\
\hline 22 & Bureaucracy in tendering method & 3.538 & Manipulation of suppliers & 3.250 \\
\hline 23 & Wrong estimation method & 3.462 & Absence of construction-cost data & 3.250 \\
\hline 24 & Contractual procedure & 3.462 & Economic instability & 3.250 \\
\hline 25 & Project financing & 3.462 & Inflationary pressure & 3.250 \\
\hline 26 & Fraudulent practices and kickbacks & 3.462 & Number of projects going at the same time & 3.250 \\
\hline 27 & Government policies & 3.385 & Wrong estimation method & 3.125 \\
\hline 28 & Level of competitors & 3.385 & Previous experience of contract & 3.000 \\
\hline 29 & Relationship between managers and labors & 3.308 & Relationship between managers and labors & 3.000 \\
\hline 30 & Disputes on site & 3.308 & Level of competitors & 3.000 \\
\hline 31 & High machinery maintenance cost & 3.154 & Bureaucracy in tendering method & 2.875 \\
\hline 32 & Previous experience of contract & 3.154 & Fraudulent practices and kickbacks & 2.875 \\
\hline 33 & Frequent changes in design & 3.154 & Waste on site & 2.750 \\
\hline 34 & High interest rates by bankers & 3.077 & Disputes on site & 2.750 \\
\hline 35 & Cost of labor & 3.077 & Effects of weather & 2.750 \\
\hline 36 & Number of competitors & 3.000 & Project financing & 2.500 \\
\hline 37 & Political situation & 3.000 & Cost of insurance & 2.500 \\
\hline 38 & Project location & 2.923 & High machinery maintenance cost & 2.500 \\
\hline 39 & Social and cultural impacts & 2.615 & Political situation & 2.375 \\
\hline 40 & Effects of weather & 2.615 & High interest rates by bankers & 2.375 \\
\hline 41 & Cost of insurance & 2.385 & Government policies & 2.375 \\
\hline
\end{tabular}

\section{References}

[1] Abadir H. Yimam (2011). Project management maturity in the construction industry of developing countries (the case of Ethiopian contractors). M. Sc. Thesis, University of Maryland, USA.

[2] Ali A.S. and Kamaruzzaman S.N. (2010). Cost performance for building construction projects in klang valley. Journal of Building Performance 1:1 P110-118.

[3] Azhar, N., R.U. Farooqui and S.M. Ahmed, 2008. Cost Overrun Factors in Construction Industry in Pakistan. Proceeding of First International Conference on Construction in Developing Countries (ICCIDE-1), Karachi, Pakistan, 4-5 August, pp: 499-508, Retrieved from: http:// www.neduet. edu.pk/Civil/ICCIDC-I/ Conference \% 20 Proceedings /Papers/ 051. pdf, (Accessed on: May, 2015).

[4] Chabota Kaliba, Mundia Muya and Kanyuka Mumba (2008). Cost escalation and schedule delays in road construction projects in Zambia. International Journal of Project Management.

[5] Ethiopian Construction Industry Development Policy (ECIDP), (2014). Approved by Ministry mikir bet, published by December 2014.

[6] Harold Kerzner (2009). Project Management: a system approach to planning, scheduling and controlling, tenth edition. John Wiley \& Sons, Inc., Hoboken, New Jersey.

[7] Ibrahim Mahamid and Nabil Dmaidi (2013). Risks Leading to Cost Overrun in Building Construction from Consultants' Perspective. Organization, technology and management in construction · an International journal 5:2 P 860-873.

[8] Larry Rich man (2002). Project Management: Step by Step. AMACOM, a division of American Management Association, NY, USA

[9] Li-Yin Shen, Andrew Platten and X.P. Deng (2006). Role of public private partnerships to manage risks in public sector projects in Hong Kong. International Journal of Project Management 24 P 587-594.

[10] Luka Goji Tipili and Muhammad Sa'adiya Ilyasu (2014). Evaluating the impact of risk factors on construction projects cost in Nigeria. The International Journal Of Engineering And Science (IJES) 3:6 P 2319 - 1805.

[11] Mahamid, I and Amund, B (2012) 'Cost deviation in road construction projects: the case of Palestine'. Australasian Journal of Construction Economics and Building, 12:1 P 58-71

[12] Nahid, G. (2003). Understanding Reliability and Validity in Qualitative Research 8 P 597-607.

[13] Nega, F. (2008). Causes and effects of cost overrun on public building construction projects in Ethiopia. Master thesis, Addis Ababa University, Addis Ababa, Ethiopia. 
[14] Olawale, Y., and Sun M. (2010). "Cost and time control of construction projects: Inhibiting factors and mitigating measures in practice." Construction Management and Economics, 28:5 P 509 - 526.

[15] Operational Selection Policy (OSP), (2005). The selection of case files: sampling technique. The National Archives, UK. Accessed on January, 2015 http://webarchive.nationalarchives.gov.uk/20080107210935/ht tp:/www.nationalarchives.gov.uk/documents/osp0.pdf

[16] PMI (1996). Project Management Institute. A Guide to the Project Management Body of Knowledge.

[17] Sekaran, U. (2001). Research methods for business: A skills building approach (2nd Ed.). New York: John Wiley \& Sons,
Inc.

[18] UNDP (2014). Ethiopia: quarterly economic brief. Accessed on http://www.et.undp.org/content/dam/ethiopia/docs/Economic \%20Brief-\%20Third\%20Quarter-2014.pdf

[19] UNDP, (2014). Country Economic Brief: Ethiopia. Accessed on

http://www.et.undp.org/content/dam/ethiopia/docs/Country\%2 0Economic\%20Brief\%201\%20final\%20for\%20web.pdf

[20] Weinberg, S. and Abromowitz, S. (2008) Statistics Using SPSS An Integrative Approach. Cambridge University Press, Cambridge.

[21] Yamane, T. (1967) Statistics: An Introductory Analysis, Harper and Row. 